\title{
Arbor
}

\section{El viaje de Federico Gravina a Constantinopla en 1788}

\section{José María Sánchez Molledo}

Arbor CLXXX, 711-712 (Marzo-Abril 2005), 727-744 pp.

En este artículo comentamos el viaje a Constantinopla de Federico Gravina en el año 1788. Apuntamos las líneas generales de las relaciones del Gobierno de Carlos III con el Imperio Otomano para señalar más adelante unos rasgos biográficos de Federico Gravina y las circunstancias que motivaron su viaje. A su regreso escribió la Descripción de Constantinopla, texto en el que describe la ciudad, los vestigios de su antigüedad, sus murallas, sus mezquitas, el Serrallo, sus bazares y sus calles. La obra constituye una aportación a la visión de la mentalidad ilustrada sobre el redescubrimiento de Oriente Próximo.

Las relaciones entre la Monarquía Hispánica y el Imperio Otomano fueron de abierta hostilidad durante los siglos XVI y XVII, debido a la hegemonía militar de ambos imperios que se disputan su expansión por Europa y el control del mar Mediterráneo, problema que se agrava por el fanatismo religioso de ambas partes.

Durante el siglo XVIII el cambio de dinastía producido con la instauración de los Borbones hace perder a los países ibéricos el papel de árbitros en Europa, al tiempo que el Imperio Otomano se va debilitando frente a la expansión de Rusia. Por otra parte las corrientes Ilustradas que imperan en la mentalidad europea llevan a la Monarquía Hispánica a establecer proyectos de reformas profundas en la administración del Estado, tanto en el orden interior como en la política exterior. 
En este contexto hay que situar la aproximación entre la Monarquía Hispánica y el Imperio Otomano. El interés del Rey Carlos III por establecer la paz con las regencia de Marruecos, Trípoli y Túnez, lleva al Primer Ministro, el pragmático Floridablanca a enviar en junio de 1778, a D. Juan de Bouligny, joyero, natural de alicante y establecido en Sevilla, a negociar la paz con el Sultán Otomano Abdul Hamit I (1774-1789). Bouligny llegó a Estambul el 5 de mayo de 1779 como Ministro Plenipotenciario, y tardó tres años en establecer con el Gran Visir Haggi Seid Muhamed Baxá, los Artículos de Paz y Comercio, de 14 de Septiembre de 1782, que fueron ratificados por el Rey Carlos III el 24 de diciembre de 1783 y por el Sultán Abdul Hamit I el 24 de abril de 1783.

Para reforzar la importancia del tratado, que era más psicológica que real, era necesario establecer un intercambio de regalos. Floridablanca envío a Estambul una escuadra de guerra compuesta por dos navíos y un bergantín al mando del Brigadier de Marina D. Gabriel de Aristizábal que partió de España el 24 de abril de 1784 y que no llegó a Estambul hasta el 10 de septiembre del mismo año. Los representantes españoles fueron recibidos en Audiencia por el Gran Señor el 6 de octubre de 1784 y entregaron los regalos, entre ellos una magnífica tienda de campaña, una vajilla de oro, otra de plata, y numerosos cajones de piezas de tisú de oro y plata, otros con chocolate, cacao, quina y tabaco en polvo.

La estancia de Gabriel de Aristizábal en Estambul se prolongó durante 43 días, escribiendo un informe de la misma que con el título de Viaje a Constantinopla fue publicada en Madrid por José Moreno, en 1790. También se hicieron cuarenta mapas y planos de Estambul y del Bósforo, así como plantas y alzados de edificios, alguno de los cuales publicamos en este artículo. El 24 de octubre de 1784 regresaba Aristizábal a España, arribando al puerto de Cartagena el 31 de mayo de 1785.

El protocolo hacía necesaria la devolución de la visita, por lo que Vasif Efendi vino a España como Enviado Extraordinario. Se embarcó en un navío francés el 1 de julio de 1787 desde el puerto de Tophane, llegando a Barcelona el 25 del mismo mes. Tras pasar la cuarentena, hizo su entrada el la Ciudad Condal el día 22 de agosto, con un numeroso séquito. Viajando por Valencia y Cuenca, llegó a San Ildefonso (Segovia), donde fue recibido por Carlos III el 30 de septiembre. Entregó al Rey de España tres sillas de montar, seis escopetas guarnecidas, telas orientales, café etc. Posteriormente fue a cazar con el Rey en El Escorial y visitó Madrid. 
El 1 de abril de 1788 partía Vasif Efendi con su séquito desde Cartagena en una escuadra mandada por Federico Gravina y Nápoli, llegando el 12 de mayo a Estambul. D. Juan de Bouligny comunicaba al Rey de España la llegada de Vasif Efendi en estos términos: «Respecto a Vasif Efendi, por ahora no cesa de hacer elogios de la benignidad, generosidad y magnificencia de Su Majestad y de nuestra Corte en términos de reconocimiento y gratitud, asegurando a este ministro que la España es una gran potencia y amiga íntima de la Puerta» ${ }^{1}$.

Durante los 31 días de estancia de Federico Gravina y su tripulación en Estambul visitaron la ciudad de la que quedaron maravillados. La vista les pareció magnífica. Escriben: Se ven a cada paso casas, lugares y arboledas; las vueltas que da el canal y el ángulo que forma en el lado izquierdo la torre no permiten ver ninguna pequeña parte de él, así parece unida la costa de Asia a la de Europa, cuyo lado también está lleno de casas y entre ellas una y un jardín del Gran Señor, y toda la costa llena de árboles, todo lo que unido forma un conjunto, el más hermoso que pueda verse, y que no tiene igual según la mayor parte de los viajeros afirman, y asi a nosotros nos lo pareció cuando fondeamos $\prime^{2}$. Se interesaron por la arquitectura de Santa Sofía, de las mezquitas, la basílica-cisterna, el Serrallo, el Bazar, los hamanes, y los alrededores de la ciudad como las Islas Príncipe, etc.

Durante su estancia en Estambul residieron en los navíos y fueron recibidos por el cuerpo diplomático establecido en la ciudad. El inicio del tiempo caluroso amenazaba con la extensión de una epidemia de peste, por lo que se les aconsejó regresar a España. El 12 de julio salieron de Estambul, llegando el 14 de agosto al puerto de Cartagena.

A su regreso a España, y durante la travesía, escribieron la Descripción de Constantinopla, escrita por los oficiales de la fragata Rosa, mandada por don Federico Gravina, en que se restituyó el embajador turco a su país, texto que fue entregado a Carlos III en noviembre de 1788. El texto se conserva manuscrito en la Real Biblioteca de Madrid y consta de 163 folios. Es una descripción de la ciudad de Estambul y de la administración otomana en la segunda mitad del siglo XVIII, vista con los ojos del movimiento ilustrado europeo ${ }^{3}$.

La Descripción de Constantinopla de Federico Gravina constituye una aportación de primer orden al conocimiento de las relaciones hispano-turcas durante el siglo XVIII y es una visión de la mentalidad ilustrada europea sobre la cultura y el mundo otomano.

En las páginas siguientes vamos a exponer unos datos sobre el viajero y su obra. 


\section{Federico Gravina y Nápoli}

Nacido en Palermo el 12 de septiembre de 1756, después de haber cursado estudios en el colegio Clementino de Roma, pasó a España, sentando plaza de guardiamarina en la compañía de Cádiz el 18 de diciembre de 1775 .

Su primer destino de embarco fue en el navío San José. En Marzo del año siguiente fue ascendido a alférez de fragata, embarcando en la fragata Clara, perteneciente a la escuadra del marqués de Casa-Tilly, que llevó a cabo la expedición contra las colonias portuguesas, transportando a las costas de Brasil al ejército del General Ceballos. Conquistada la isla de Santa Catalina, Gravina fue comisionado para intentar la rendición al castillo de la Ascensión, lo que consiguió sin resistencia. En el Río de la Plata, el 27 de febrero de 1777, dejando la escuadra su fondeadero cercano a la boca, la fragata Clara equivocó su rumbo, naufragando en los bancos del Inglés, y Gravina fue uno de los pocos que se salvó del naufragio; llegó a Montevideo en una lancha y allí paso destinado a la mayoría general, embarcando en el navío San José, y pasando después al San Dámaso, con el que regresó a Cádiz.

Ascendido a alférez de navío a mediados del año 1778, embarcó sucesivamente en los jabeques Pilar y Gamo, con los que cruzó por el Mediterráneo contra los corsarios argelinos, hundiendo a cuatro de ellos en un combate. Una vez ascendido a teniente de fragata, se hizo cargo del mando del San Luis y con él concurrió al bloqueo de Gibraltar. Por su brillante actuación fue promovido al empleo de teniente de navío, dándosele el mando del apostadero de Algeciras en destino de superior categoría. Fue destacado a las fuerzas del general Ventura Moreno para la expedición de Menorca y en ella se distinguió en el ataque al fuerte de San Felipe. Terminada esta campaña volvió a su apostadero, a hostilizar y bloquear de nuevo a Gibraltar. Ascendido a capitán de fragata, mandó la flotante San Cristóbal.

Como capitán de navío, embarcó a las órdenes del general Luis de Córdoba en el Trinidad, hallándose en la acción que dicho almirante sostuvo contra la escuadra inglesa del almirante Howe; ésta, al fin, pudo pasar el estrecho aprovechando un furioso temporal y aprovisionar la plaza de Gibraltar, cosa que trataba de evitar la escuadra española. A la vuelta al océano tuvo lugar otro nuevo encuentro, regresando la escuadra a Algeciras. Gravina volvió a tomar el mando del San Luis, en el que hizo algunas presas; firmada la paz, lo llevó a Cartagena.

En 1783 tomó el mando de la fragata Juno, que formó parte de la escuadra de Barceló en el ataque a Argel. En él se le dio el mando de todas 
El viaje de Federico Gravina a Constantinopla en 1788

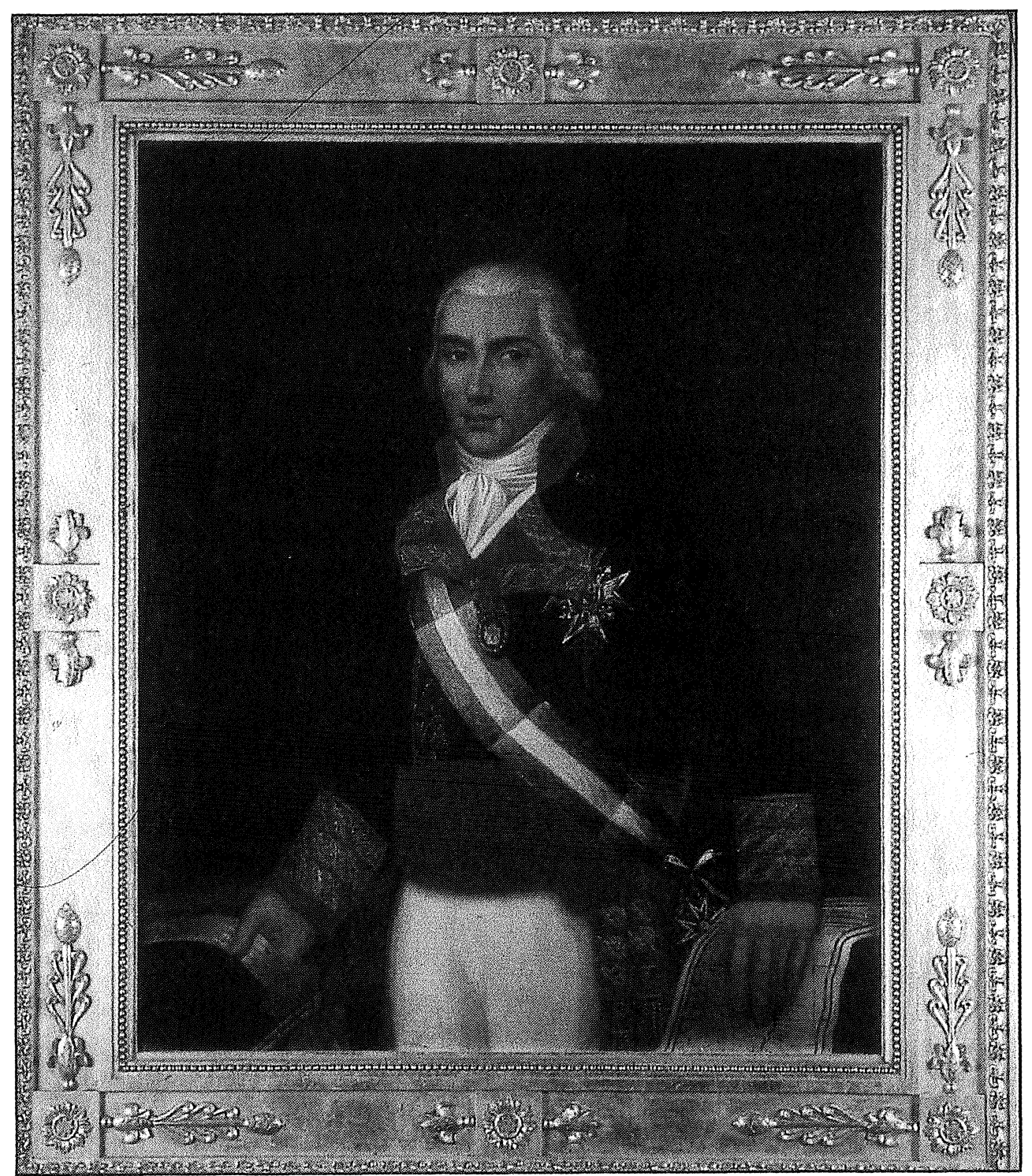

FIGURA 1. Retrato de Federico Gravina y Nápoli. Museo Naval. Madrid 
las lanchas encargadas del fuego cercano. En la campaña del año siguiente volvió Gravina mandando toda la división de Poniente, arbolando su insignia en el jabeque Catalán. Mantuvo un bloqueo riguroso, rechazando los contraataques que realizaron las fuerzas enemigas, suministrando además valiosos datos de la plaza. Los malos tiempos hicieron que los barcos españoles tuviesen que dejar las aguas argelinas y regresar a Cartagena.

En 1787 se encomienda a Federico Gravina el mando de la fragata Santa Rosa, perteneciente a la escuadra de evoluciones del general Lángara. Realizó con ella cruceros de instrucción.

\section{El viaje de Federico Gravina a Constantinopla en 1788}

El día 18 de enero de 1788 recibió Federico Gravina en el puerto de Cádiz la Real Orden de pasar a Cartagena para desde allí dirigirse a Constantinopla llevando al embajador turco. El 12 de febrero salió de Cádiz y el 18 llegó a Cartagena, donde tuvo la Real orden de movilizarse pronto y poner la fragata en disposición de poder transportar con la decencia y comodidad posible al enviado de la Corte otomana, Acmet Guasiff Effendi, que fue el primero que con tal carácter vino a nuestra Corte después de la firma de la paz con Turquía ${ }^{4}$.

Por carta de 22 de marzo de 1788, Federico Gravina informa que puede dar vela el día 29 si antes recibe el dinero necesario para el transporte ${ }^{5}$, y por carta de 29 de marzo comunica que está listo para dar la vela cuando le entregen los dos mil doblones sencillos para los gastos. El día 30 recibe orden de salir esa misma tarde.

El día 1 de abril, al amanecer llegaron los equipajes del Embajador turco, y a las 10 de la mañana llegó el embajador, estando a las 11 listos, dando la vela. Gravina informa que tuvieron tres días de viento de poniente bonancible y favorable, llegando hasta las islas de Mallorca y Menorca. En las inmediaciones de esa última tuvieron un día de viento contrario, y en la noche, estando en frente del Golfo de León sobrevino de repente sobre una tumbonada, un furioso norte que hizo pedazos todas las gavias. Luego abonanzó dicho viento y llegaron en un día a la vista de Cerdeña. En ocho días llegaron a Sicilia.

Encontrando el 8 de abril unos navíos de la religión de Malta, envió Gravina a su ayudante el teniente de navío D. Joaquín Valdés a cumplimientar el general, quien le cuenta que unos días antes había entrado en el puerto la fragata Santa Magdalena que los turcos habían obligado a 


\section{El viaje de Federico Gravina a Constantinopla en 1788}

salir de Constantinopla diciendo que no querían que buque alguno de país extranjero subsistiese en su puerto. El comandante D. Luis de Villavicencio arribó a la Isla de Malta a las 4 de la tarde, donde entregó un pliego de la Corte, adquirió noticias de Constantinopla y reemplazó la aguada.

Los días 10 y 11 no pudieron salir por el viento contrario. El Enviado turco rescató siete esclavos que se embarcaron como miembros de su comitiva. Gravina y sus oficiales vieron al Gran Maestre de Malta. Por fin, remolcada la fragata por 35 botes, salieron el 12 de abril de Malta. El día 16 de abril recalan sobre el cabo Arcadia e islas de la Sapiencia en la Morea. Vientos contrarios les obligan a buscar el abrigo de la isla del Cerico en la embocadura del archipiélago, y envían con un bote al alférez de navío D. Pedro Valdecano. Pasaron a la isla de Mitilene, y desde ésta a la de Scio. Continuaron por el golfo de Napoli, de Romania, de las islas de Milo, Argentero, Sensamo, islas Zea y Longa, y las islas de Hesane y Mitilene. Gravina anota en su Diario de navegación: «...a cuyas islas y demás, tan famosas del archipiélago en el tiempo que florecieron los griegos y los romanos, ya solo el nombre les ha quedado de lo que fueron, pues apenas han quedado algunas ruinas de sus antiguos templos. Nosotros solo hemos visto en el cabo Colonna un triste avance del famoso templo, y se ven todavía formado un ángulo de un cuadrilátero con trece grandes columnas, nueve a un lado y cuatro al otro»6.

El día 1 de mayo, pasaron entre la isla de Tenedos y la costa de Asia, donde estuvo la antigua Troya. Gravina escribe: "Costeamos a menos de media milla toda la costa donde fue la ciudad de Troya, pero no observamos los mínimos vestigios de sus ruinas, y si todo campo labrado, pues los sultanes para fabricar las grandes mezquitas que hay en Constantinopla han hecho transportar todas las piedras y mármoles que habian quedadon?.

El día 3 de mayo entraron en el Canal de los Dardanelos, donde señala que tienen dos castillos, situados en la mayor angostura del canal: Punta Europa y Cabo Janízaro (sic), que tienen su pequeña ciudadela y los han fortificado nuevamente por ingenieros franceses después de la última guerra con los rusos en el año 1769. Señala que siempre sale la corriente de este canal por las aguas que proceden del mar Negro.

El día 3 de mayo fondearon en el castillo de Asia en los Dardanelos, donde estuvieron seis días. Allí fue el Cónsul de España. Señala Gravina que no está permitido el paso de ningún buque de guerra entre los dos castillos si no tiene el firmán que el cónsul presenta al Bajá Agá o gobernador del castillo. Lo barcos mercantes no necesitan este requisito. 
Allí fueron registrados en la Aduana para ver si llevaban géneros de contrabando. El día 8 de mayo escribía Bouligny a Floridablanca dando cuenta de la noticia del arribo de la fragata Santa Rosa a los Dardanelos. Informa igualmente "la peste continua en esta capital, aunque no con el mayor fomento ${ }^{8}$. Por su parte, la tripulación de la fragata Santa Rosa fue informada de la peste por la fragata francesa La Hiris, mandada por el caballero Orleans. Tomaron precauciones: comprando comida, antes de recibirla a bordo la pasaron por agua salada.

El 6 de mayo recibieron el firmán, el día 7 intentaron pasar el canal, lo que no les permitió el viento SO y las corrientes. Por fin el día 9 de mayo a las 10 de la mañana pasaron el canal de los Dardanelos. Saludaron con dos cañones de aviso, a los que respondieron los turcos con 13 cañonazos cada castillo, "tirando según su costumbre con balas de piedra, y de hierro, pasando varias de ellas inmediatas al buque, observamos que alcanzaban de un castillo al otro, y las vimos caer sobre la arena de la parte opuesta»". Gravina ordenó saludar con 26 cañonazos, "devolviendo tiro por tirom, a lo que los turcos respondieron con dos en respuesta a los dos primeros de aviso.

A partir de este punto, comenzaron a ver la ciudad por la parte de la puerta de Andrinópoli, y siguiendo delante el castillo de las Siete Torres, donde reside el príncipe heredero. La vista les pareció magnífica. Escriben: «Se ven a cada paso casas, lugares y arboledas, las vueltas que da el canal y el ángulo que forma en el lado izquierdo de la torre no permiten ver ninguna pequeña parte de él, así parece unida la costa de Asia a la de Europa, cuyo lado también está lleno de casas y entre ellas una y un jardín del Gran Señor, y toda la costa llena de árboles, todo lo que unido forma un conjunto, el más hermoso que pueda verse, y que no tiene igual según la mayor parte de los viajeros afirman, y así a nosotros lo pareció cuando fondeamos» ${ }^{10}$.

El día 12 de mayo de 1788, a las dos de la tarde llegó la fragata Santa Rosa al puerto de Constantinopla. Desembarcó Vasif Effendi, "quien tanto en esta ocasión como en toda la navegación se manifestó muy contento del modo con que lo habíamos tratado, y del obsequio que siempre le habiamos hecho". Gravina envío al teniente de fragata D. Cayetano Valdés con un pliego de la Corte para el enviado D. Juan Bouligny, a quien fue a ver con todos los oficiales y guardiamarinas, quienes fueron al día siguiente a comer a su casa, para más tarde visitar a los embajadores y ministros extranjeros.

D. Juan de Bouligny enviaba noticia a la Corte de esta llegada, en carta de 15 de mayo, en estos términos: "El día 12 fondeó en este puerto la 
nombrada Santa Rosa al mando de D. Federico Gravina, conduciendo de transporte al Ministro Plenipotenciario de la Puerta con su comitiva, que inmediatamente se desembarcó muy satisfecho y agradecido del trato y agasajo que ha experimentado durante la navegación de parte del comandante y oficiales. Gravina me ha traído carta del Sr. Valdés de 14 de marzo por la que me encarga se cuenta con este buque para la elección prescrita en R.O. de 21 de febrero respecto a permanecer en este destino arreglada a las reales ordenes y a las circunstancias en esta fecha le contesto, que tomaré con el referido comandante la resolución la más conveniente, de que daré parte a V.E. por el primer correo.

Respecto a Vasif Effendi, por ahora no cesa de hacer elogios de la benignidad, generosidad y magnificencia de S.M. y de nuestra Corte en términos de reconocimiento y gratitud, asegurando a este ministro que la España es una gran potencia y amiga intima de la Puerta. Anteayer le cumplimenté sobre el feliz arribo, y me envió las Cartas de S.M. para el Sultán y Gran Visir, y las de V.E. para el mismo y Capitán Bajá, suplicando le hiciese una traducción en francés que facilitase la lectura y poder presentarlas al Gran Señor y demás, le complací al instanten ${ }^{11}$.

El 13 de mayo fue el ayudante D. Joaquín Valdés a cumplimentar de parte de D. Federico Gravina al Capitán Bachá que estaba anclado con su escuadra compuesta de 36 buques entre navíos, fragatas y otros menores, a la boca del mar Negro aguardando viento favorable para dar a la vela.

Subieron a Pera, lugar de residencia de los miembros del cuerpo diplomático, y fueron a casa de Bouligny, quien por estar enfermo envió a su hijo, D. Juan Bouligny, Secretario de Embajada, a acompañarles para visitar según costumbre a todos los embajadores y ministros extranjeros, quienes devolvieron el mismo día la visita al comandante y oficiales en casa del enviado o embajador de España. Comieron en casa de Bouligny.

El 14 de mayo recibieron por medio de Bouligny, la noticia del nacimiento de una Infanta de España, hija de la Princesa. Con tal motivo engalanaron los navíos, y a las tres de la tarde dispararon 21 cañonazos. El día 15, se vistieron todos de gala y fueron a saludar a nuestro Enviado por el suceso. Comieron en casa del embajador de Inglaterra, y por la noche celebraron fiesta a bordo, con asistencia de más de cincuenta señores.

Gravina y sus oficiales estuvieron 31 días en Constantinopla. Anotan en el Diario que estuvieron varias veces en la ciudad a ver sus grandes mezquitas, los panteones, sus mercados, las fábricas exteriores del Serrallo, las principales plazas, calles y demás fábricas públicas, fueron varias veces al canal del mar Negro, y a las islas del Príncipe, y a varios pa- 
José María Sánchez Molledo

736

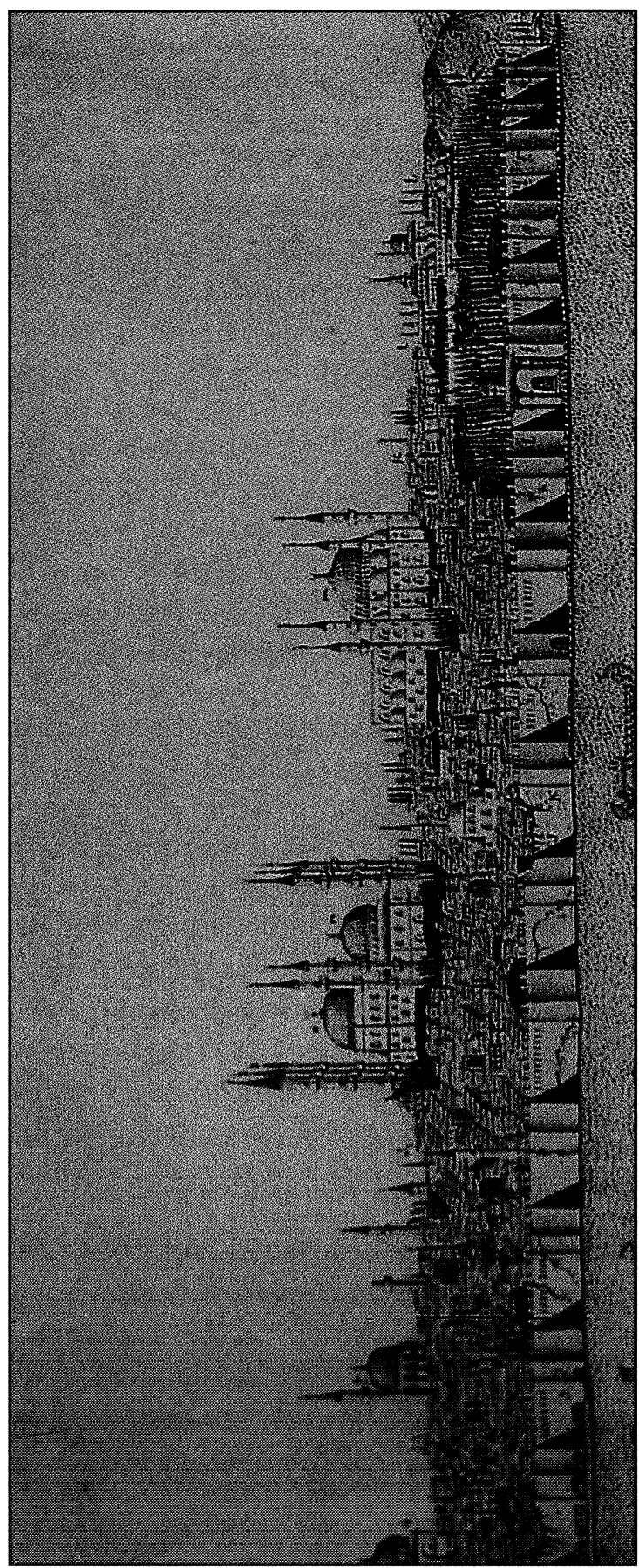

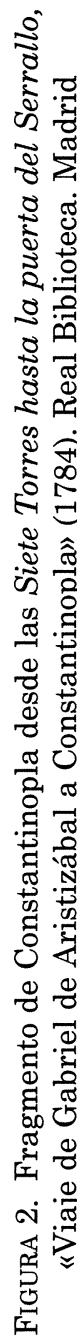


rajes de la costa de Asia como en Calcedonia, en Scúteri, en Condili, estuvieron en el Arsenal y demás obra de marina, vieron varias casas de campo del Gran Señor y sitios de recreo, y demás obras públicas.

El 16 de mayo fueron a pasear a Pera, al campo de los muertos, donde entierran a los cristianos, griegos y armenios, donde hay un espeso arbolado, y es el mayor parque para ver la ciudad. Vieron gitanos y muchas turcas, quedando sorprendidos por verlas en grupos y sin ningún hombre que las acompañase.

El sábado 17 fueron a Aguas Dulces, sitio de recreo del Gran Señor, "sitio delicioso por lo frondoso de sus árboles como por una presa de mármol donde las aguas que vienen del monte formando varios estanques, desembocan en el canal de donde venimos, $y$ de sus aguas da el nombre» ${ }^{12}$.

El domingo 18 de mayo invitaron a comer a bordo, para celebrar el feliz nacimiento del Infante D. Carlos todos los embajadores, enviados, encargados de negocios y secretarios de embajada y sus señores, acudiendo 32, vestidos de gala. Pusieron los retratos de S.M. y de sus altezas los príncipes. El día 19 fueron a comer en casa del embajador extraordinario de Nápoles, y el 20 a cenar en casa del Bailo de Venecia. Por la noche celebró una gran fiesta de baile, donde concurrieron casi todos los señores del país.

El 21 de mayo fueron a ver la ciudad, acompañados por un dragomán y dos jenízaros. Así lo narran los protagonistas: Vieron... "por fuera las principales mezquitas, Santa Sofía, Solimán y Sultán Hahmet. Después fuimos a ver el mercado, es un vaso grande y donde una gran cantidad de judíos, de turcos y dè armenios venden todas las estopas de Asia y todos los géneros de lienzos de algodón y de hilo, todas las especies de Cerdeña, $y$ de Nápoles. Todos estos están en una sola fábrica, hay después otras varias calles contiguas anexas, a lo que llaman mercado, donde venden lanas, algodón, sables, alhajas de oro y plata, tafiletes, etc, y reina en estos parajes el buen orden como en cualquier otra ciudad politica.

Dicha fábrica del mercado es muy vasta, pero oscura y sin primor alguno. Todas las casas generalmente en Constantinopla son feas y pequeñas por fuera, unas pegadas a otras, y todas de madera. Las calles también feas, estando mal empedradas y sucias, y sólo una hemos visto buena, que atraviesa casi toda la ciudad.

Fuimos a la plaza dicha del hipódromo, es grande y tiene en el medio una aguja sobre el gusto de los egipcios que hay en Roma, pero mucho más pequeña. Vimos el panteón del presente Gran Señor, donde están enterrados sus hermanos e hijos»"13.

El 22 de mayo fueron a comer a las islas del Príncipe, que describe, donde fueron invitados por el enviado de Suecia. Comieron en el cam- 
po. El 23 de mayo fueron los oficiales a comer en casa del enviado de Prusia.

Por carta de Bouligny a Floridablanca de 22 de mayo, comunica la sugerencia recibida, de hacer regresar en la fragata Santa Rosa al ministro marroquí con su comitiva, quien llegó a Constantinopla a bordo de la Santa Cecilia, esperando Bouligny contestación de la Corte ${ }^{14}$.

El 24 de mayo tuvieron las primeras noticias de algún accidente de peste. Por la tarde fueron a ver el arsenal y los buques de guerra que estaban anclados y preparados para salir al archipiélago. El día 23 fueron a Belgrado, en las proximidades de la ciudad. Fueron a caballo. Anotan que a una milla del lugar hay un gran estanque que recibe el agua de los montes inmediatos, de donde pasa a Constantinopla. Comieron en casa del embajador de Holanda y cenaron en casa del enviado de España. El 26 de mayo por la tarde, fueron al cementerio de los turcos en Gálata.

El 27 de mayo fueron a ver los monumentos de la ciudad: Estuvimos varios oficiales, acompañados por un dragomán y dos jenízaros en Constantinopla a ver la mezquita de Santa Sofía, que es la más antigua, y fabricada por Constantino emperador para el culto divino, y para ver todas las particularidades dignas de atención. Salimos de a bordo temprano, y fuimos a desembarcar en un muelle de madera, de los que hay varios al redondo de la ciudad, pero ninguno es de piedra, ni hecho con algún primor, a pesar de que en varios de ellos desembarca el Gran Señor los viernes cuando va a la mezquita.

Entrados en la ciudad, fuimos primero a ver Santa Sofía, que es la mezquita más grande que hay. Tiene dos cuerpos, en el primero van los turcos a orar, está cubierta de esteras y con muchas lamparillas, haciendo varios círculos. Hay dos púlpitos como los nuestros a los lados y dos más bajos, pero más grandes y cuadrados, donde sólo suben los de la ley.

Tanto el cuerpo bajo como el alto están revestidos de mármoles muy finos y sostenidos de columnas de granito, las paredes donde no los cubren los mármoles están adornadas de mosaicos, el vaso es alto y la cúpula bastante grande, pero sin tener ninguna comparación con la de San Pedro, que será tres veces mayor en todas sus partes.

En el cuerpo alto hay contiguas varias piezas que eran todas revestidas de mosaicos, pero ahora apenas se ve señal de ello, pues los que los cuidan venden a cualquiera los pedazos de ello. Yo compré varios por un duro.

En el cuerpo bajo de la izquierda en la entrada dicen está sepultada la hija de Constantino. El Gran Señor tiene una tribuna particular hacia 


\section{El viaje de Federico Gravina a Constantinopla en 1788}

el fondo de la iglesia y hay otra para sus hijos y tiene entrada aparte, y lo mismo en las demás mezquitas.

Alrededor de la mezquita por fuera, a los cuatro vientos hay cuarto agujas con un caracol al interior, a cuyo extremo suben los derviches para llamar al pueblo a las horas de orar, que son particularmente a las 12 del día y de la noche en tiempo de Ramadán, y en este tiempo iluminan con candilejas dichas agujas, que hace hermosa vista como hemos observado en los dias de Ramadán que nos hemos hallado.

Más tarde fuimos a ver la casa que llaman la Puerta, donde está el Diván y donde prende la justicia y donde tiene su audiencia el Reis Efendi. Antes de entrar en dicha casa hay una puerta grande pero lisa y sin ninguna magnificencia, $y$ de ella deriva este nombre, se entra en el primer patio y se ve una casa sin nada de particular, ni de grandioso, y lo mismo se observa en otro patio que le sigue, asi, ni por dentro ni por fuera tiene nada vistoso ni digno de verse, a no ser por el nombre que tanta curiosidad mueve, por lo mucho que de ello siempre se habla y se nombra la sublime Puerta» ${ }^{15}$.

"Pasamos después a la casa del Serrallo, tiene un recinto muy grande con su muralla que lo circunda; la puerta por donde se entra al primer patio es grande pero sin magnificencia alguna, a la izquierda en la entrada hay un poyo donde se ponen las cabezas de los decapitados. En este primer patio es fácil el ingreso. Allí dentro vimos la casa de la moneda, vimos todas las piezas de los artífices, y hacen acuñar todas las monedas. Todos los cuartos destinados a obradores son indecentes, y no hay ninguna buena.

Vimos después el panteón del Sultán Hacmet, donde se distinguían los ataúdes del Sultán y de su hermano y de sus hijos, por un turbante que tenía encima el Sultán.

A lo último fuimos a ver la Cisterna, que llaman de mil y una columnas, en donde están en el día los que trabajan la seda y pagan por ello una cierta cantidad al Gran Señor. Está en un alto de la ciudad y se baja a ella por una mala escalera. Contamos 250 columnas y cada una es de 3 , una encima de otra, de la mayor parte se ven las dos caras, pero la tercera nos dijeron estaba enterrada, pues echaron dentro de dicho vaso todos los escombros cuando hicieron la mezquita de Solimani, que está inmediata. Las paredes que sostienen dicha fábrica que es cuadrada, son muy espesas, según parecen por dentro y por fuera, no se ven, pues el piso de la ciudad está casi a nivel del techo, donde por algunos agujeros se comunica la luz a dicha cisterna. Algunos pretenden que no fue cisterna, sino un templo de los antiguos, y que sirvió después para refugiarse los cristianos 
en el tiempo de las persecuciones, pero la mayor parte dicen que fue cisterna, y este es el nombre que le dan. Lo cierto es que es la cosa más digna de verse en Constantinopla por su tamaño y cantidad de columnas.

El día 28 de mayo fueron a merendar a Bardo, y el viernes 29 de mayo fueron a Büyükdere con el Secretario de Embajada y su mujer, $D^{a}$ Teresa Timoni, señora franca de Pera, a comer en casa del embajador de Venecia. Poco antes de las 12 vieron salir al Gran Señor de su palacio inmediato al arsenal. Vieron la falúa del Gran Señor con la proa guarnecida de piedras preciosas y esmeraldas de bastante tamaño. Se dirigía a la mezquita, donde entró con un cortejo de caballos ricamente enjaezados.

El 31 de mayo fueron a comer en casa del embajador de Inglaterra, donde vieron varios planos del canal, del mar Negro y de diferentes vistas de la ciudad y sus cercanías, varios planos de templos y edificios antiguos de Grecia. Gravina pidió permiso para hacerse copiar los primeros por un pintor que estaba en su casa, permiso que le fue concedido.

El 31 de mayo, el enviado de España, comunica que con los calores, y en el barrio franco, se está produciendo mayor fomento de la peste, por lo que conviene la salida de Constantinopla, en dirección a Malta, comunicando que en cuatro días tendría el firmán para el paso de los Dardanelos.

El 1 de junio fue a comer a bordo el encargado de negocios de Holanda, y por la tarde fueron a Pera, donde supieron de la existencia de nuevos casos de peste. El 2 de junio fueron a la punta de Calcedonia, antigua ciudad en la que se celebró el Concilio, de la que no queda nada. A 4 leguas de dicha ciudad está el sepulcro de Aníbal.

El 3 de junio fueron a la isla del Príncipe, a comer en casa del enviado de Suecia. Vieron en castillo de las Siete Torres.

El 4 de junio fue a comer a bordo el secretario de la embajada, con el fin de ir por la tarde a ver dos quioscos del Gran Señor, Sólo fueron autorizados a ver uno de ellos. Allí "encontramos varios bostanchi, que mediante que los regalamos nos dejaron ver todo y nos trajeron café según acostumbran". Vieron una casa hecha y amueblada a la turca, de un armenio rico, sobrino del Sr. Abate que les acompañaba. Al anochecer volvieron a Pera, donde oyeron que en Gálata habían muerto cinco de peste.

El día 5 fueron a Büyükdere, a comer en casa del embajador de Venecia. Por la tarde fueron a la Montaña del Gigante, en carretas.

El 6 de junio fueron a ver el mar Negro. El enviado comunicó que en la mañana siguiente pasaría el oficio para la salida y enviaría los firmanes de la Puerta. 


\section{El viaje de Federico Gravina a Constantinopla en 1788}

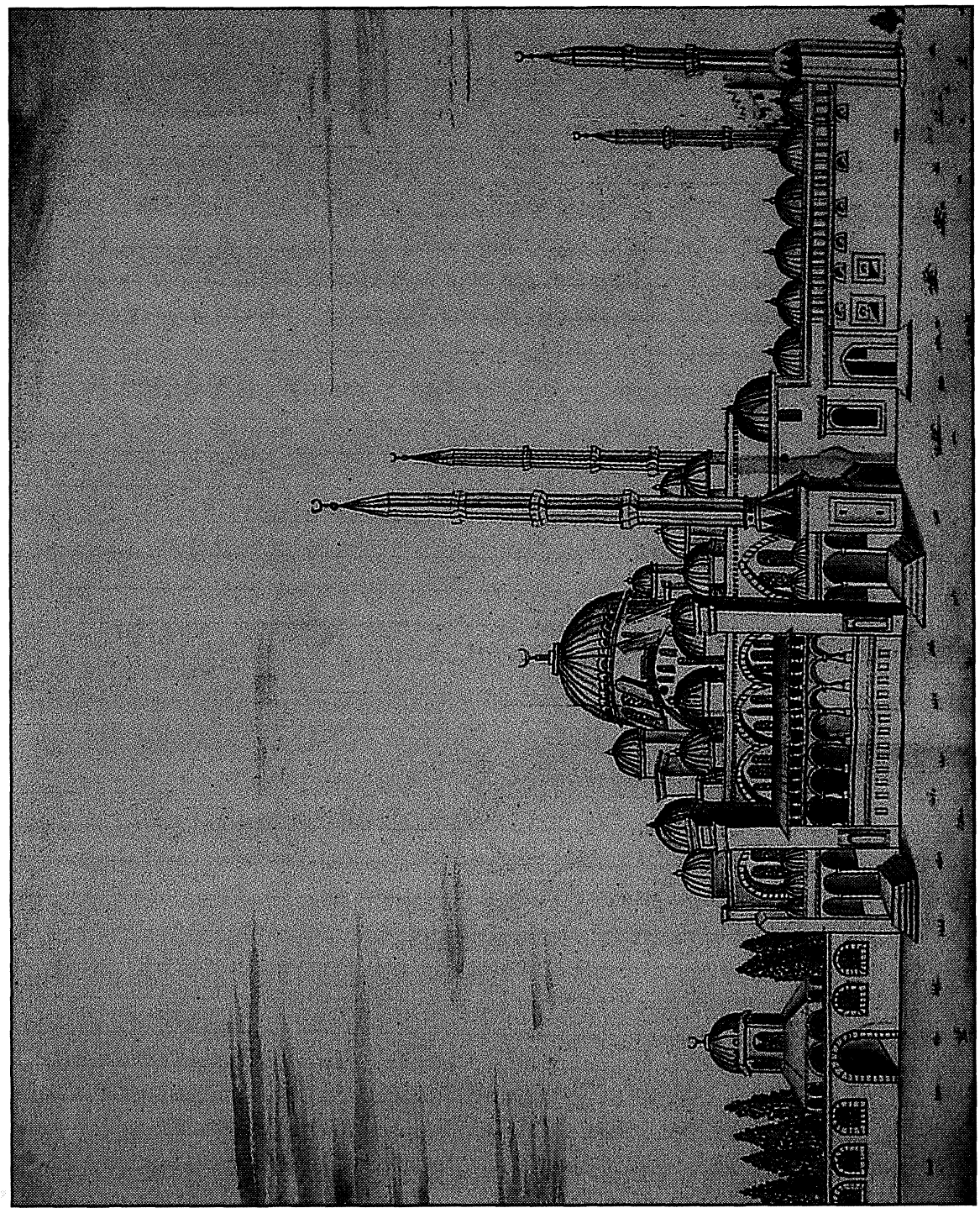

告 
El 7 de junio, después de la comida a bordo, Bouligny envía una carta a Gravina por la que aconseja la salida de la ciudad por la epidemia de peste, aguardando en Malta las órdenes del monarca, adjuntando dos firmanes de la Puerta otomana con sus traducciones, para el pase de los Dardanelos y otros para cualquier puerto donde pueda ser forzoso arribar ${ }^{16}$. Gravina respondió al enviado que estaba listo, y que daría a la vela en la tarde del día siguiente si el tiempo lo permitía.

El día 8 se mantuvo el viento del sur, no haciendo posible la salida. Fueron a comer en casa de Bouligny, y por la tarde, a ver las iglesias católicas.

El 9 de junio continuó el viento sur y el tiempo revuelto, sin permitir la salida. Fueron a casa del Barón de Ambs, a ver sus baños turcos. Más tarde fueron al baile de los derviches.

El 10 y 11 de junio continuó la calma y los vientos contrarios. Por fin al amanecer el 2 de junio con un pequeño viento del norte, a las 8 de la mañana, habiendo tomado un poco de fuerza el viento dio a la vela la fragata Santa Rosa.

El 13 de junio estaba frente a Galípoli, el 14 pasaron entre los dos castillos de los Dardanelos, el 15 pasaron el Negroponto y las islas Longa y Zea, y el 16 estaban en Candía. El día 27 de junio estaban cerca del puerto de Malta, donde fondearon. A las 8 llegó la visita de la sanidad, a quien se dio la relación de los enfermos, entre los que se contaban siete hombres con calentura. Allí pasaron la cuarentena, llegando a tener 29 hombres enfermos y 24 convalecientes. El 3 de julio pasaron la cuarentena.

El 14 de agosto de 1788 fondeó en el puerto de Cartagena, procedente de Alicante, al que había llegado desde Constantinopla, el bergantín Infante, con carta del comandante de la fragata Santa María Magdale$n a$, dando cuenta de que quedaba en cuarentena y necesitaba víveres ${ }^{17}$. Por su parte, Federico Gravina saló el 8 de septiembre de la isla de Malta, habiendo recibido el día anterior la Real Orden de su regreso a Cádiz. El 14 pasan frente a la Bahía de Túnez, el 20 pasaron la isla de Mallorca y el 28 de septiembre antes del medio día rebasaron el Estrecho, entrando en el puerto de Cádiz a las cinco y media de la tarde. El día 12 de octubre recibió Federico Gravina, orden para el desarme de la fragata. El día 13 pasó para el Arsenal de la Carraca, y el día 20 quedó desarmada y sus pertrechos colocados en su almacén. Así termina el Extracto del Diario de Federico Gravina en su viaje a Constantinopla, fechado en la Carraca, a 20 de octubre de 1788.

Carlos III llamó a la Corte a Federico Gravina, tomó el camino de Madrid, llevando en el cofre la relación de lo ocurrido, titulada por él "Des- 
cripción de Constantinopla, escrita por los oficiales de la fragata Rosa, mandada por don Federico Gravina, en que se restituyó el embajador turco a su país". En Madrid, el Ministro Valdés lamentó que la peste no le hubiera dejado trazar entera la carta del Mediterráneo oriental, se interesó por las observaciones astronómicas que había hecho, y lo acompañó a Palacio el día que fue a presentar la Memoria a su Majestad.

El Rey Carlos III murió unos días más tarde, el 14 de diciembre de 1788. Federico Gravina fue ascendido hasta general en jefe de la escuadra. Fue herido en la batalla de Trafalgar (21 de octubre de 1805), a consecuencia de la cual murió en Cádiz a los pocos meses. Sus restos pasaron en 1883 al Panteón de Marinos ilustres, en San Fernando.

\section{La descripción de Constantinopla}

Texto manuscrito, se conserva en la Real Biblioteca de Madrid. Tiene una extensión de 163 folios. Se estructura en 6 capítulos. En el primero describe la ciudad y sus monumentos: el Serrallo o palacio del Sultán, las principales mezquitas reales: Santa Sofía, Sultán Ahmet, Süleymaniye, Sultán Bayaret, Sultán Mohamed IV, Sultán Selím y Sultán Mohamed, y otras. Describe los bazares y los hanes o caravasares.

El capítulo segundo lo dedica al Serrallo y a las costumbres de la Corte otomana: la vida el sultán, el harén, el príncipe sucesor y los otros príncipes.

El capítulo tercero está dedicado a la administración del imperio otomano, dedicando epígrafes a los empleos civiles y a las fuerzas militares de la armada y de tierra, para concluir con las rentas del imperio.

El capítulo cuarto lo dedica a las costumbres de los turcos, con una introducción sobre la vida de Mahoma. El capítulo cinco está dedicado a los usos de los turcos, como las casas y comidas, las mujeres, y el carácter de la nación turca.

El último capítulo está dedicado a los demás habitantes de Constantinopla, entre los que señala los francos, los rayás, los armenios, los griegos, los judíos y los alepinos.

En conjunto es un resumen sistematizado que permite aproximarse a los ojos con los que la Europa de la Ilustración veía al imperio otomano, que estaba en una etapa de decadencia. Federico Gravina se muestra interesado en la obra por las obras de la antigüedad, por el sistema defensivo, por el protocolo de la Corte y por el sistema de vida, escribiendo un texto de alto interés documental. 


\section{Bibliografía}

FERnÁNDEZ DE CASTRo, C. (1956): El almirante sin tacha y sin miedo: Vida del Capitán General de la Armada española Don Federico Gravina y Napoli. Imp. Escelicer, Cádiz.

GarRigues DíAZ-CAÑabate, E. (1962). Un desliz diplomático. La paz hispano-turca. Revista de Occidente, Madrid.

Gravina, F. (1788). SÁnchez Molledo, J.Ma . (Editor literario) (2001): Descripción de Constantinopla. Miraguano, Madrid.

Jurado Aceituno, A. (2001). A propósito de Vasif Efendi, primer embajador turco en España y el informe de su estancia. Cervantes 19-25, Estambul.

Meynard, B. (1862) Ambassade de l'historien turc Vaçif Efendi en Espgne (1787 - 1788); traduit sur la relation originale. Journal Asiatique, 19 505-523, París.

Moreno, J. (1784) Viaje a Constantinopla. Imprenta Real, Madrid.

SÁNCHEZ Molledo, J.Mª (2002). El viaje de Federico Gravina a Estambul en 1788. Cervantes 24-27, Estambul.

SÁNChEZ ORTEGA, M. H. (1989) Las relaciones hispano-turcas en el siglo XVIII. Hispania 171, 151-195, Madrid.

\section{Notas}

1 A.H.N. Estado, leg. 4.746. Correspondencia de D. Juan de Bouligny.

2 Gravina, F.: Extracto del Diario de Navegación a Constantinopla. Mss. 20 de octubre de 1788 .

${ }^{3}$ Hemos publicado nuestra transcripción del manuscrito: Gravina, F.: Descripción de Constantinopla, Madrid, Miraguano, 2001.

${ }^{4}$ Gravina, F.: Extracto del Diario del Capitán de navio D. Federico Gravina, comandante de la fragata Santa Rosa en su viaje a Constantinopla transportando el enviado de la Corte otomana Acmet Guasif Effendi, y varias noticias observadas y adquiridas en aquella capital. Mss. 42 fols. Museo naval. Mss. 2.485.

5 A.H.N. Leg. 4.746. Carta de Federico Gravina a D. Antonio Valdés.

6 Gravina, F.: Extracto del Diario..., fol. 3 ro.

7 Ibidem, fol. $3 \mathrm{v}^{\mathrm{o}}$.

8 A.H.N. Estado, leg. 4.746.

${ }^{9}$ Ibidem, fol. $6 \mathrm{v}^{\mathrm{o}}$.

10 Gravina, F.: Extracto..., fol. $18 \mathrm{v}^{\mathrm{o}}$.

11 A.H.N. Estado, leg. .4746.

12 Gravina, F.: Diario..., fol. $20 \mathrm{v}^{\mathrm{o}}$.

13 Ibidem, fol. $21 \mathrm{v}^{0}$.

14 A.H.H. Estado, leg. 4.746.

15 Ibidem, fols. $22 \mathrm{v}^{\circ}$ y $23 \mathrm{r}^{\mathrm{o}}$.

16 A.H.N. Estado, leg. 4.746.

17 Archivo Bazán, leg. 128. Expediciones a Europa. 